\title{
The Path to Fusion Energy for Concepts Currently at the Concept Exploration Level
}

\author{
E.B. Hooper
}

January 13, 2003

U.S. Department of Energy

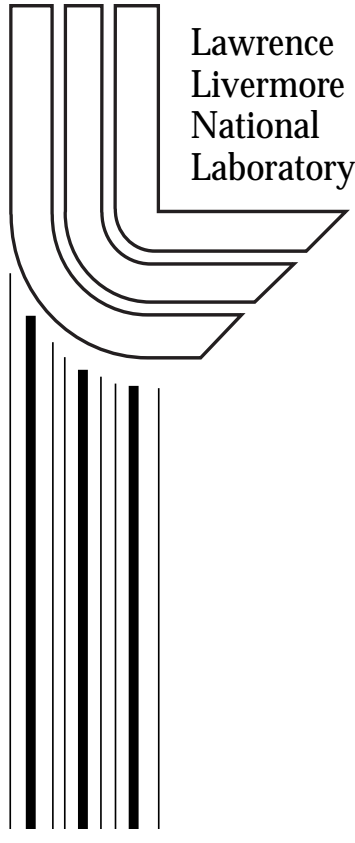




\section{DISCLAIMER}

This document was prepared as an account of work sponsored by an agency of the United States Government. Neither the United States Government nor the University of California nor any of their employees, makes any warranty, express or implied, or assumes any legal liability or responsibility for the accuracy, completeness, or usefulness of any information, apparatus, product, or process disclosed, or represents that its use would not infringe privately owned rights. Reference herein to any specific commercial product, process, or service by trade name, trademark, manufacturer, or otherwise, does not necessarily constitute or imply its endorsement, recommendation, or favoring by the United States Government or the University of California. The views and opinions of authors expressed herein do not necessarily state or reflect those of the United States Government or the University of California, and shall not be used for advertising or product endorsement purposes.

This work was performed under the auspices of the U. S. Department of Energy by the University of California, Lawrence Livermore National Laboratory under Contract No. W-7405-Eng-48.

This report has been reproduced directly from the best available copy.

Available electronically at http://www.doe.gov/bridge

Available for a processing fee to U.S. Department of Energy and its contractors in paper from

U.S. Department of Energy

Office of Scientific and Technical Information

P.O. Box 62

Oak Ridge, TN 37831-0062

Telephone: (865) 576-8401

Facsimile: (865) 576-5728

E-mail: reports@adonis.osti.gov

Available for the sale to the public from

U.S. Department of Commerce

National Technical Information Service 5285 Port Royal Road

Springfield, VA 22161

Telephone: (800) 553-6847

Facsimile: (703) 605-6900

E-mail: orders@ntis.fedworld.gov

Online ordering: http://www.ntis.gov/ordering.htm

OR

Lawrence Livermore National Laboratory

Technical Information Department's Digital Library

http://www.llnl.gov/tid/Library.html 


\title{
The Path to Fusion Energy for Concepts Currently at the Concept Exploration Level
}

\author{
E. B. Hooper \\ Lawrence Livermore National Laboratory \\ Livermore, CA 94551 \\ January 13, 2002
}

\section{Overview}

Concept Exploration (CE) experiments ${ }^{1}$ within the Innovative Confinement Concept Program have a unique role which impacts their contributions to the development of fusion energy. As stated in the FESAC "Report on Alternate Concepts:" ${ }^{2}$

These [CE] programs are aimed at innovation and basic understanding of relevant scientific phenomena.

The emphasis on innovation motivates their application to the search for a better fusion reactor configuration. In addition, because of their unique character the CE experiments offer excellent opportunities to couple fusion-plasma physics to other sciences. A recent example of coupling is the fusion self-organized plasmas to reconnection physics and extra-terrestrial plasmas. Perhaps of even greater importance is the education of the future scientists needed for developing fusion energy. The CE experiments, both at universities and national labs, are of a size students can "get their hands around;" young scientists and engineers will be attracted by this intellectual challenge combined with the vision of lowpollution energy for mankind represented by a burning-plasma experiment.

A CE concept showing promise for fusion energy is expected to advance to the Proof-of-Principal stage. Experience has shown that this progression may occur in several ways: NSTX followed from success in START, a CE-level experiment in England; NCSX built on a broad base of theory and a strong international stellarator data base, without a CE experiment to test quasiaxisymmetry; and MST is following an upgrade path from the CE experiment of the same name (albeit at a budget much less than the other PoPs). The lesson to be learned is a highly positive one, namely that the portfolio approach - with its five stages of development - is being applied in a flexible and pragmatic manner without artificial constraints from strategic planning. This lesson also makes it clear that as we move towards the development of fusion energy we need to determine the best way forward for each promising configuration, taking advantage of its unique attributes.

The reactor embodiment of a CE concept may look much like an improved tokamak or may, in some visions, be very different. This may result in more complex decision points or in zig-zags in progress towards the energy application as the science behind the concept becomes better understood. The resulting innovations may shorten the time to fusion energy; alternatively, 
maturation of the development path may cause the reactor embodiment of the concept to follow (in time) testing of a tokamak reactor. The long-term success of fusion energy requires us to be flexible in our plans, while recognizing that issues of handling large powers and energy, mitigating neutron damage, and many other practical matters cannot be delayed for the discovery of the "best" reactor configuration.

Finally, most CE concepts involve more complex physics than the tokamak. This places them at a significant disadvantage for rapid deployment: Because their budgets are low, it is difficult to develop sufficiently the scientific knowledge needed to justify an experiment at the PoP stage. Success in moving to this level will need the use of sophisticated diagnostics to generate the data needed to guide and demonstrate understanding, coupled (in many cases) to advanced computational modeling of the complex phenomena. These are both relatively expensive undertakings, suggesting that progress forward may often be more of a continuous process with small steps than a discontinuous jump from the CE to the PoP level. MST is an example of such a progression. Innovative use of advanced diagnostics, perhaps on more than one experiment but certainly drawing on collaborations among researchers, may prove to be cost effective. Plans for advanced modeling, such as that by the ongoing ISFOS Panel to develop a roadmap for a Fusion Simulation Project, need to explicitly recognize the needs of the ICCs in general and the CEs in particular.

\section{Example Development Plans}

Because of the diversity of the CEs, it is useful to consider three example development plans which essentially span the experiments underway or envisioned in the program:

- Toroidal confinement concepts. A reactor based on these may look, at least superficially, much like a tokamak. However, they offer opportunities which may significantly change the reactor design with implications for the development path; these include pulsed reactor options and an increased possibility of utilizing liquid walls to minimize material damage from neutrons. Examples are the spheromak and field-reversed configuration (FRC). To be specific, we will focus on the spheromak but the plan is essentially generic in nature.

- Concepts which operate in a very different plasma parameter space. An example is magnetized target fusion (MTF) which operates at parameters intermediate to MFE and IFE. MTF involves magnetized fusion fuel heated by a high-power imploding medium (e.g., solid metal or "liner," liquid metal, or high-density plasma), which implies a pulsed reactor scenario similar in many respects to inertial fusion.

- Non-toroidal concepts which are in the early exploratory stage and which are very different from the tokamak. These typically are funded at a rather low level, so that the reactor concepts are more primitive than for the first two 
categories. Examples include the ZAP (Flow Z-Pinch) and Electrostatic Confinement; we choose ZAP as characteristic of this category, although the broad range of concepts makes description of a generic development plan difficult.

The following briefly describes the status of the three experimental programs and of existing reactor concepts. Advancing to a reactor will require success in the ongoing experiments followed by a number of decision points. The ICC-CEs have the opportunity to accelerate their development by building on the tokamak knowledge base and by applying tools developed for it, thus bypassing several of the scientific steps it took. Still, if and as the concept moves into a PoP sized device and beyond, increased attention to advanced diagnostics and modern computational simulations will be required to close the gap with the tokamak. If successful, the ICC programs may be able to reduce the number of steps to DEMO; in that event, a CE has a reasonable chance of being ready in time for consideration for the DEMO.

\section{Toroidal CE concepts}

We use as an example the spheromak. At present there is one moderatesized experiment, the Sustained Spheromak Physics Experiment (SSPX), funded at $<\$ 3 \mathrm{M}$ / year." Several university groups have installed diagnostics on SSPX, and a small theoretical effort, including application of the NIMROD resistive MHD code, complements the experimental effort. In addition, a second experiment, HIT-SI is being constructed; it will inject helicity (effectively current drive) in a very different manner than SSPX. The research also benefits from physics synergies with the RFP.

The CE experiments are designed to address relatively narrow physics issues, with progression to PoP status when sufficient success justifies the application of the necessary resources. (It is recognized that there is some "blurring" of the boundary between CEs and PoPs in real experiments.) SSPX is focused on the issues of energy confinement and the buildup of magnetic flux and current at electron temperatures $>>100 \mathrm{eV}$. Experimental results to date ${ }^{3}$ include electron temperatures of $>250 \mathrm{eV}$ in plasmas when the spheromak is operated with magnetic fluctuations $\sim 1 \%$; energy confinement in the core corresponds to $\chi_{\mathrm{e}}<30 \mathrm{~m}^{2} / \mathrm{s}$. It is anticipated that a sufficiently good understanding of this physics will be developed in the next few years that a decision on proceeding can be made, together with a judgment of the best potential reactor configuration. This judgment is expected to have major impact on the design of future experiments.

There have been several spheromak reactor studies which provide a vision for progress towards the energy goal. The most detailed, by Hagenson and Krakowski ${ }^{4}$ described a toroidal reactor without the toroidal field coils required in a tokamak. The outside plasma radius was $1.7-3 \mathrm{~m}$. A very high neutron

* None of the CE experiments are funded at the maximum $\$ 5 \mathrm{M} /$ year recommended in the IPPA document. 
wall power density was assumed, close to $20 \mathrm{MW} / \mathrm{m}^{2}$; in the present understanding of neutron damage, this would probably have to be reduced significantly. Mitigation of materials damage would be required, as in a tokamak reactor. Never-the-less, this design is a good starting point for a "standard" reactor.

The reactor vision includes options which depart significantly from a "tokamak-like" power plant. There have been several recent studies of reactor applications utilizing technologies which are possibly more suitable to the spheromak than to the tokamak. Perkins considered a "boiling pot" reactor ${ }^{5}$ in which the first wall is surrounded by liquid lithium (to generate tritium) with an admixture of sodium and potassium, which evaporated and carried the heat to a turbine. Recognizing the gains to follow from protecting solid walls from neutrons, Fowler, et al., considered a pulsed reactor, with lithium walls which were expelled by plasma pressure following a rapid plasma burn. ${ }^{6}$ Hooper and Fowler made a preliminary analysis of a steady state reactor with liquid walls; ${ }^{7}$ later, Moir et al. generated a design of a steady state reactor with the walls protected by liquid salt or metal flowing along magnetic fieldlines ${ }^{8}$. Although further effort is needed to make this fully self consistent, it demonstrated the features of such a device. Bourque, et al., ${ }^{9}$ have considered a reactor based on repetitive merging of spheromaks. Absent a fuller understanding of spheromak physics, these designs should to be considered illustrative of what might be achievable; nevertheless they suggest opportunities which may be possible with CE toroidal concepts.

A timeline connecting the present experiments to possible reactors is shown in Fig. 1. As the CD concept matures, it evolves from a single experiment to a program involving multiple contributors. Decision points play a much larger role than in development paths for concepts which are further along than spheromaks. In particular, if an "advanced" reactor concept is chosen, there will have to be a supporting technology effort to take advantage of the reactor opportunity offered. An example of such a technology is the development of thick, flowing liquid walls. This development might reduce the dependence of the resulting DEMO on the nuclear materials development, as most reactor components would see much lower neutron fluxes than the conventional (walled) concept.

Cost of the development program is difficult to predict accurately given that present uncertainties in the physics extrapolate to uncertainties in size, heating power, and other cost drivers in future experiments. A rough estimate is shown in Table 1 using existing IPPA guidelines. It is important to differentiate between experiments and programs. In the case of the CEs which show strong promise, a lead experiment should be funded at about $\$ 5 \mathrm{M}$, as called for by the IPPA; with a supporting experiment and additional support, the cost will be two - three times this, or $\$ 10 \mathrm{M}$ to $\$ 15 \mathrm{M}$. The PoP program will also include supporting CE experiments, etc. The construction costs for existing PoP experiments range from $\$ 20 \mathrm{M}-\$ 30 \mathrm{M}$ (with significant site credits) for NSTX to \$75M for NCSX. (MST is an upgrade with no "construction" cost, although with 


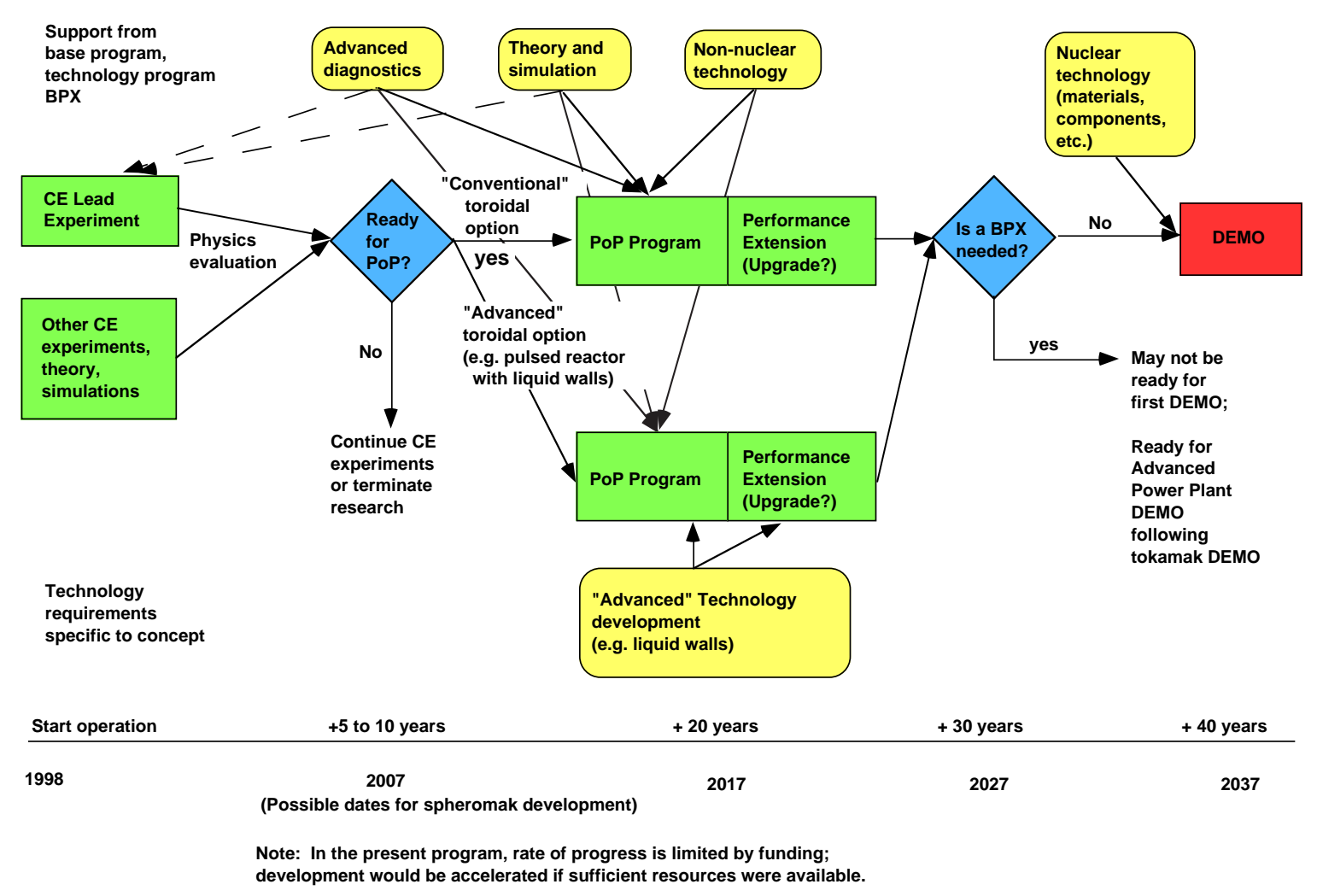

Fig. 1. Timeline for $\mathrm{CE}$ Toroidal Configuration emphasizing major decision points along the development path. Time scales are approximate and depend on physics progress and resource availability. Support from diagnostics, theory and simulation, and non-nuclear technology will be required.

additional budget above the $\mathrm{CE}$ experiment for equipment and diagnostics and for operations.) The spheromak is considerably less complex than NCSX, so the PoP construction should be closer to that of NSTX; if site credits are less, a cost of $\$ 30 \mathrm{M}$ is plausible.

Operating costs would increase from the $\$ 3 \mathrm{M}$ - $\$ 5 \mathrm{M} /$ year of a $\mathrm{CE}$ experiment to the $\$ 20 \mathrm{M}$ - $\$ 30 \mathrm{M}$ typical of NSTX, and the theory and simulation(T\&S) support would increase from the present $\sim \$ 0.3 \mathrm{M}$ to several $\mathrm{M} \$$. In the timeline shown, it is assumed that the transition from PoP to PE will utilize an upgrade path; it is likely that the cost will require an additional $\$ 30 \mathrm{M}$ $\$ 50 \mathrm{M}$ and operating costs will increase to the $\$ 50 \mathrm{M}$ level of DIII-D. Theory and simulation is likely to require a corresponding increase in support.

The program as described utilizes many of the supporting science and technologies (e.g. diagnostics, theory and simulation, nuclear technology) being carried out in the base and tokamak programs; only incremental costs are included here. The budget also assumes that the nuclear technologies being developed by the base technology program will be applicable. In the event of a significant innovation such as the use of a thick liquid wall, the cost of the nuclear materials program could be significantly decreased. Because the development of the alternative concept is proceeding in parallel with the tokamak, however, such a cost savings would likely come only in the late stages of development. 


\begin{tabular}{|c|c|c|c|}
\hline Cost Category & Cost/year (\$M) & Duration (years) & Total Cost (\$M) \\
\hline \multicolumn{4}{|c|}{ Concept Exploration (2 experiments and supporting research) } \\
\hline \multicolumn{4}{|c|}{ Exp. \#1 } \\
\hline Construction & 1 & 2 & 2 \\
\hline Operations & $3-5$ & 8 & $24-40$ \\
\hline \multicolumn{4}{|l|}{ Exp. \#2 } \\
\hline Construction & 1 & 2 & 2 \\
\hline Operations & $3-5$ & 8 & $24-40$ \\
\hline T\&S & $0.3-0.5$ & & $2.4-4$ \\
\hline \multicolumn{4}{|c|}{ Proof of Principle (1 PoP and 1 CE experiment and supporting research) } \\
\hline \multicolumn{4}{|c|}{ PoP exp. } \\
\hline Construction & $5-7$ & 4 & $20-30$ \\
\hline Operations & $20-30$ & 10 & $200-300$ \\
\hline \multicolumn{4}{|l|}{ CE exp. } \\
\hline Construction & 1 & 2 & 2 \\
\hline Operations & 3-5 & 8 & $24-40$ \\
\hline T\&S & $2-3$ & & $20-30$ \\
\hline Technology & 5 & & 50 \\
\hline \multicolumn{4}{|c|}{ Performance Extension } \\
\hline Const./ upgrade & $7-12$ & 4 & $30-50$ \\
\hline Operations & 50 & 10 & 500 \\
\hline $\mathrm{T} \& S$ & 10 & & 100 \\
\hline Technology & 10 & & 100 \\
\hline Total & & 38 & $1100-1300$ \\
\hline
\end{tabular}

Table 1. Possible cost of development to DEMO for a CE toroidal concept using IPPA guidelines. Estimates are based on costs in the tokamak (PE) and ICC-PoP programs and are rough. Not included are costs such as nuclear materials development which are assumed bourn by the lead program.

One goal of this development path is to bypass the BPX stage and proceed directly to a DEMO. Success in this goal is dependent on integrating the knowledge gain from ITER (or other BPX) into this program. Such integration will be possible only if physics understanding and computational simulation continue to improve, achieving sufficient confidence to skip the experimental step. It is probably not possible at this time to predict whether this will actually happen. If it does not, the CE toroidal concept will be ready for a DEMO in 35 years only if progress in the program occurs more quickly than historically has happened, e.g. due to application of advanced diagnostics and simulations, and proceeds at a rapid rate along the development path. 


\section{Magnetized Target Fusion}

MTF $^{10}$ operates in a plasma density regime intermediate to MFE and IFE; c. f. Figure $2{ }^{11}$ The reactor concepts are pulsed, with compression of a target plasma by a liquid wall raising the plasma to the densities and temperatures needed for the fusion reaction. The figure also shows several confinement scalings; because of the high density, the plasma is much less sensitive to the energy confinement than MFE. Complications include wall interactions, for example possible mixing of the wall with the hot plasma. The effective confinement time for the fusion plasma is essentially the "dwell time" at high compression, $\sim 0.1-1 \mu \mathrm{s}$; at this duration and with these plasma parameters, the alpha particles contribute little to plasma heating. ${ }^{12}$ On the positive side, because of the low plasma temperature ( 7 to $8 \mathrm{keV}$ ) relative to MFE burning or ignited plasmas, alphas have a small beta relative to the primary plasma. Thus their effect on plasma stability, beta, etc., is small so that the need to study this physics is considerably less important than in MFE plasmas. ${ }^{12}$

Active research is presently focused on developing a FRC target plasma using the Field Reversed Experiment - Liner (FRX-L) ${ }^{13}$ at LANL with a small theoretical effort exploring options for targets, ${ }^{14,15}$ advanced physics issues ${ }^{16}$ such as stability, the plasma - liner interface, etc. Initial results from the FRX-L experiment at Los Alamos National Laboratory have demonstrated that the desired parameters for liner implosion can be achieved (higher-density when compared with other typical FRC experiments). ${ }^{17}$ Densities of $3-5 \times 10^{16} \mathrm{~cm}^{-3}$ are typical with estimated temperatures $\mathrm{T}_{\mathrm{e}} \approx \mathrm{T}_{\mathrm{i}} \approx 60 \mathrm{eV}$, beta $\approx 0.9$ and lifetime $\approx 8 \mu \mathrm{sec}$, consistent with excluded flux measurements. End magnetic fields are cusped to aid the formation stage and mirror-like during the equilibrium period to axially confine the FRC. Further experiments are required to demonstrate higher temperature $\mathrm{T}_{\mathrm{e}} \approx \mathrm{T}_{\mathrm{i}} \approx 200-300 \mathrm{eV}$ FRC's for MTF target plasmas suitable for

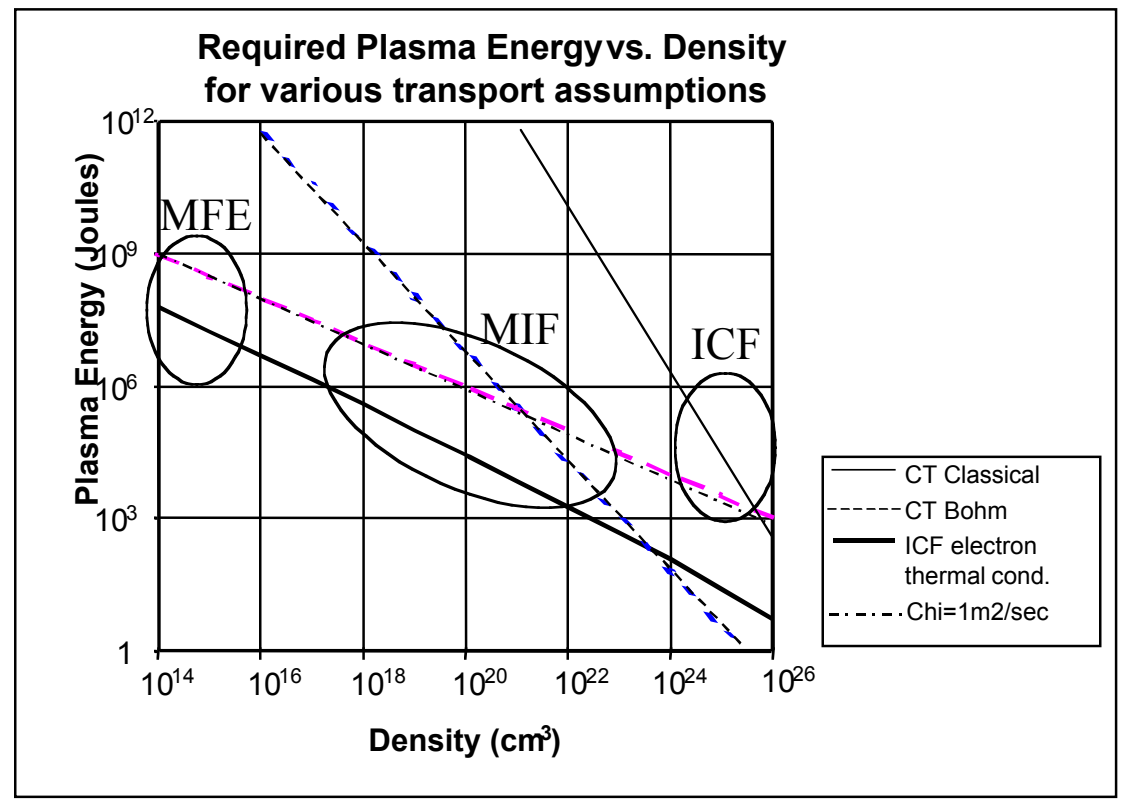

Fig. 2. Operating regime for MTF relative to MFE and IFE. ${ }^{11}$ 
translation and compression to fusion conditions. To help seed the next generation of fusion scientists and engineers, many $(\approx 25)$ undergraduate and graduate students have been involved in FRX-L over the last 3 years.

There has also been experimental work on imploding liners. Degnan, et al. ${ }^{18}$ used the Shiva Star capacitor bank (5 MJ) to compress a $\sim 1 \mathrm{eV}$ plasma in quasispherical geometry from an initial pressure $\sim 170$ bars to $\sim 1$ Mbar. The same capacitor bank was used for the cylindrical compression of a weak seed magnetic field (without plasma); a radial compression of $>7$ was achieved ${ }^{19}$ for the magnetic field (before magnetic probes failed), with $>11$ determined by radiography. ${ }^{20}$

Reactor studies for $\mathrm{MTF}^{21}$ have included both fast ( $\mu$ sec) liner and slow (msec) liner power plants. The fast liner approach might be driven by beam or kinetic energy transport of power, or might use a disposable solid electrode compatible with the blanket/coolant material. A thick liquid blanket of FLIBE has been considered to protect material walls while breeding tritium; the MTF configuration does not require that this blanket be within the plasma vacuum envelope. The slow liner ("LINUS") approach ${ }^{22}$ uses a liquid metal liner to compress the plasma. The essential issue is the recovery of the kinetic energy of the liner following implosion, made possible by rotating the liquid to avoid Rayleigh-Taylor modes at peak compression, thus maintaining control over the liquid motion throughout the compression and subsequent expansion phases. Because of the slow timescale, energy can be stored, delivered, and recovered by compressed gas, significantly decreasing cost from electrical compression schemes and enabling operation at a low fusion $\mathrm{Q}$ (as low as 1.55 in one study ${ }^{22}$ ). Fowler ${ }^{23}$ has made more recent (speculative) designs based on the LINUS approach.

The main advantage to MTF according to its advocates is that the qualitatively different parameter regime of operation allows intrinsically less costly facilities for development. A development schedule and cost estimate for MTF were made in $1999,{ }^{21}$ based on the assumption that the initial program would be funded at the PoP level. (See Fig. 3.) Although this did not happen, even with a stretched out initial phase the proposed development path is consistent with a DEMO in 35 years. The PoP and Performance Enhancement stages would use existing facilities from Defense Programs, thereby reducing costs and shortening the schedule. An Engineering Test Reactor phase would test both energy gain issues (the "burning plasma" experiment for MTF) and reprating capability in a "burst mode" approach of 10-100 pulses. The estimated cost to DEMO is $\sim \$ 650 \mathrm{M}$. The assumptions that were used for each stage were: ${ }^{21}$

PoP Use Shiva Star at Phillips Laboratory to document FRC heating to $\mathrm{keV}$ temperatures by liner implosion, with $\mathrm{Q}_{\text {equiv }}=(\mathrm{DT}$ equivalent fusion energy) $/($ liner KE) $=0.01-0.10$. 3 years at $\$ 7 \mathrm{M}$. / year $(\$ 10 \mathrm{M}$ facility already exists.)

Perf. Enhanc. Expand efforts to optimize plasma targets (spheromaks, etc.... ) Use ATLAS at the Nevada Test Site in the single-pulse mode to obtain $\mathrm{Q}_{\text {equiv }}=0.1-1.0$ in $\sim 2$ years. Optimization and assessment 
requires $\sim 7$ years at $\sim \$ 20 \mathrm{M} /$ year. ( $\$ 50 \mathrm{M}$ ATLAS facility will be available for this type of scientific research.)

ETR Choose fast or slow liner approach. Test rep-rated power supply in finite burst mode.

DEMO 250-MW unit; 1-10 GJ yield; 0.1-1 Hz; Reliable rep-rated containment. Issues of nuclear materials and tritium handling. 12 years at $\$ 80 \mathrm{M} /$ year. (Requires $\$ 800 \mathrm{M}$ facility.)
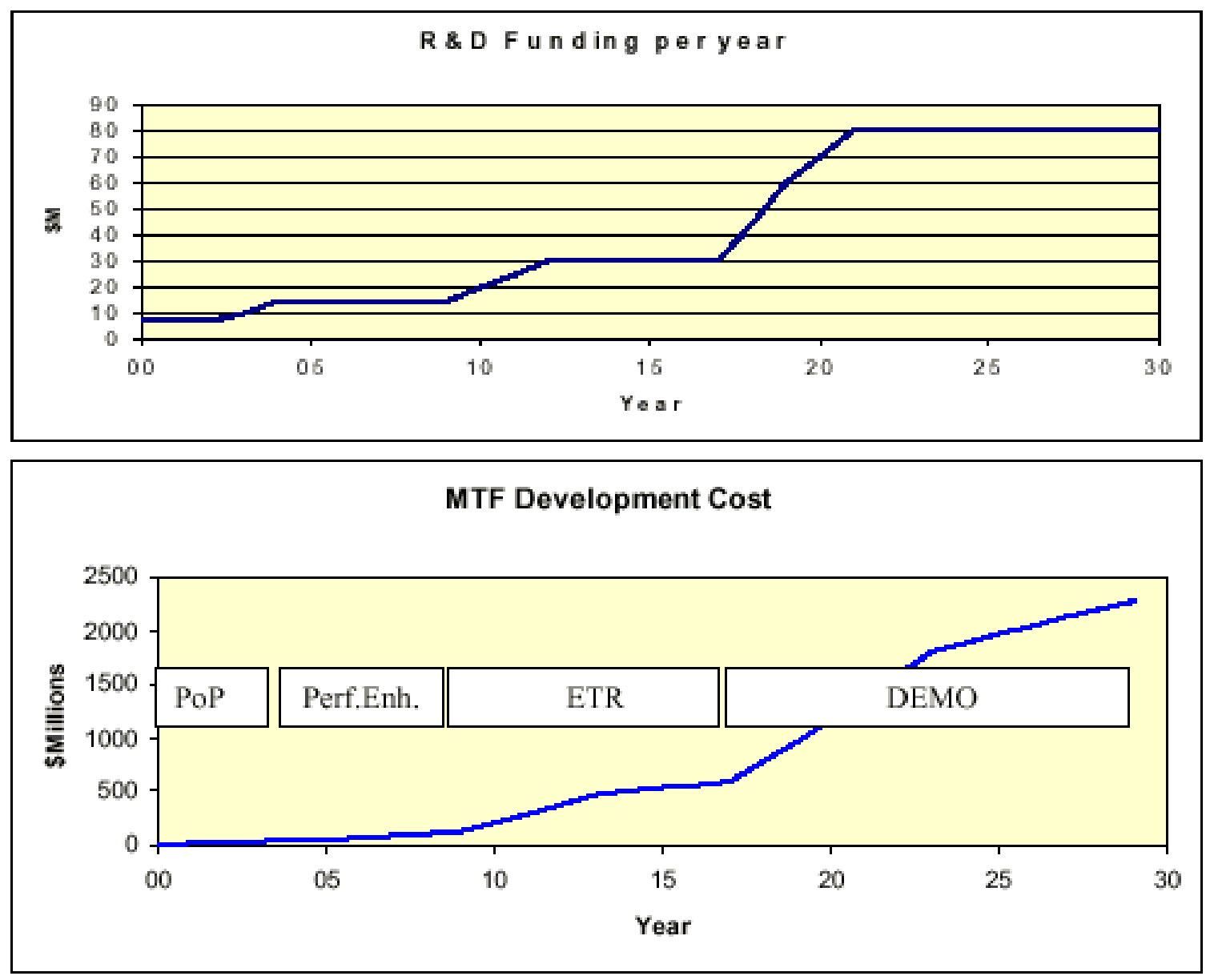

Fig. 3. Estimated development schedule and costs for MTF. (From Ref. 21) The top figure shows the operating costs; facility costs are necessary for ETR and DEMO. The bottom figure shows the cumulative cost of the proposed program.

\section{Flow Z-Pinch}

The Flow Z-Pinch is characteristic of low-cost CE experiments which address interesting physics issues pertinent to fusion energy. The visions include potentially significant reactor impacts but, because of the early stage and relatively low funding of the research, energy applications have generally not 
been analyzed in depth and development plans not considered. The work is typically done in universities, involving both graduate and undergraduate students, thereby helping to address the need for future fusion scientists and engineers to support the broader vision of energy from a fusion reactor.

The Flow Z-Pinch concept is based on calculations which indicate that the Zpinch can be stabilized with sufficiently sheared axial flow. Shumlak and Hartman $^{24}$ find that a linear (radial) shear of $v_{z} / v_{A}>0.1 \mathrm{ka}$ is sufficient to stabilize the $\mathrm{m}=1$ mode; a rather more severe condition is found by Aber and Howell ${ }^{25}$ who conclude that $v_{z}>2-4 v_{A}$ is required to stabilize all modes with $k a=10$.

In an experiment by Shumlak, et al., ${ }^{26}$ a Z-pinch with a steep velocity shear $\left(1.9 \times 10^{7} \mathrm{~s}^{-1}\right)$ at the pinch plasma edge had $\mathrm{m}=1$ and 2 fluctuation magnetic field amplitudes $\leqslant 10 \%$ for $17 \mu$ s; after that time the shear became small and the amplitude increased to $\gtrsim 20 \%$. For the experimental conditions, the stabilizing shear predicted by Shumlak and Hartman is $4.2 \times 10^{6} \mathrm{~s}^{-1}$. The flow velocity in the Z-pinch core was $\sim 0.8 v_{A}$, less than that of Aber and Howell for full stabilization. The physics results are clearly encouraging for shear stabilization, although as Shumlak, et al. ${ }^{26}$ note: "at this point causality cannot be determined."

Hartman et al. ${ }^{27}$ described a reflex-configuration geometry of the Flow ZPinch which might lend itself to a reactor. For the power reactor, issues of recycling of magnetic energy, electron thermal conduction and enthalpy loss (5/2 $\left.\mathrm{IT}_{\mathrm{e}}\right)$ would need resolution. If these losses cannot be controlled, a low $\mathrm{Q}(=0.1-$ 1) pulsed device might make a low cost fusion neutron source. The neutron power loading on the first wall could be very high $\left(\sim 100 \mathrm{MW} / \mathrm{m}^{2}\right)$ in a design concept which would utilize a spin-stabilized liquid first wall. Costs were not estimated, but the basic device is very simple, so if the physics is resolved positively costs are likely to be considerably smaller than in a tokamak or toroidal ICC reactor.

\section{Issues and discussion}

\section{$\underline{\text { Criteria for PoP decision }}$}

A critical decision in the development of a CE concept is whether to proceed to the PoP level. The basic decision criteria are defined in Fig. 2.2 of the IPPA document ${ }^{1}$, as "Physics shown to be promising; energy vision attractive." The decision process will certainly include a peer review of the proposed PoP experiment which will address the physics extrapolation and reactor vision from the CE investigations, recognizing that limited resources will have limited the scope of the experiment.

The IPPA process defines experiments at the PoP level as having an increase in resources sufficient to "develop an integrated understanding of the basic science of a concept. Well diagnosed and controlled experiments are large enough to cover a fairly wide range of plasma parameters, with temperatures of a few kiloelectron volts, and some dimensionless parameters in the power plant 
range." In the early stages of an experiment based on a $\mathrm{CE}$, the requirement that the temperatures be "a few kiloelectron volts" should probably be replaced by "in the kiloelectron volt range." MST is an example: Temperatures during the CE phase approached $1 \mathrm{keV}$, and have been further increased as the research moves into the PoP stage, but are still short of a "few" keV. There is more of a continuous improvement in both physics understanding and in parameters rather than a discontinuous step as implied by the strategic planning. This characteristic is likely to be typical of CEs as their development progresses.

\section{$\underline{\text { Resource requirements }}$}

Resource availability has been and likely will continue to be a major concern. As yet, no CE experiments have approached the $\$ 5 \mathrm{M}$ level considered to be the maximum appropriate for this stage. This slows progress and lengthens the duration of the CE experiments. Even more seriously, it can constrain the ability to make experimental and diagnostic upgrades, thus limiting the scientific results. - A stretched out program may never have sufficient resources to test ideas which could significantly advance a concept.

It is also important that concepts which show significant progress have supporting experimental, theoretical, and computational research. As the Fusion Energy Program moves into the proposed development phase, it thus is important that funding be increased sufficiently that progress at the CE stage can contribute to the fullest appropriate extent. A doubling of the available funds would generate a significant increase in the rate of progress; it still would be less than the funding (extrapolated to today's dollars) available to this category of experiments in the 1970-80 time frame.

\section{Acknowledgement}

This work was performed under the auspices of the U. S. Department of Energy by University of California Lawrence Livermore National Laboratory under contract No. W-7405-Eng-48.

1 Integrated Program Planning Activity, DOE/SC-0028, December 2000. Available at http://www.ofes.science.doe.gov/.

2. FESAC Report on Alternate Concepts, DOE/ER-0690, July 22, 1996. Available at http://www.ofes.science.doe.gov/.

3. D. N. Hill, et al., "Field and Current Amplification in the SSPX Spheromak," $19^{\text {th }}$ IAEA Fusion Energy Conference, Lyon, France 14-19 Oct. 2002, Paper IAEA-CN-94/EX/C1-3.

4. R. L. Hagenson and R. A. Krakowski, Fusion Techn. 8, 1606 (1985); see also “The Spheromak as a Compact Fusion Reactor," LANL Report LA-10908-MS, March 1989.

5. L. J. Perkins, private communication (1996).

6. T. K. Fowler, D. D. Hua, E. B. Hooper, R. W. Moir, and L. D. Pearlstein, Comments Plasma Phys. and Controlled Fusion, 1 Part C, 83 (1999). 
7. E. B. Hooper and T. K. Fowler, Fusion Techn. 30, 1390 (1996); T. K. Fowler and E. B. Hooper, Proc. 8th Intern. Conf. Emerging Nuclear Energy Systems, Obninsk, Russia, June 24-28 (1996), LLNL Report UCRL-JC-124363.

8. R. W. Moir, R. H. Bulmer, T. K. Fowler, T. D. Rognlien, and M. Z. Youssef, "Spheromak magnetic fusion energy power plant with thick liquid-walls,"

9. R. F. Bourque, P. B. Parks, and M. J. Schaffer, "RMS - Repetitive Merging of Spheromaks: A Fusion Reactor with Pulsed Heating, Fueling, and Current Drive," Innovative Confinement Concepts Workshop, College Park, MD, 2224 Jan. 2002, https:/ / wormhole.ucllnl.org/ICC2002/.

10. Background documents and reports on MTF can be found at http:// fusionenergy.lanl.gov.

11. R. E. Siemon, I. R. Lindemuth, and K. F. Schoenberg, Comments Plasma Phys. Controlled Fusion 18, 363 (1999).

12. D. D. Ryutov, Fusion Sci. and Tech. 41, 88 (2002).

13. T. Intrator et al [BP1.030] Overview of Reversed Field Configuration plasma target research at LANL for Magnetized Target Fusion, Bulletin Am. Phys. Soc., APSDPP Nov 20022 Orlando FL, http://www.aps.org/meet/DPP02/baps/abs/S200030.html.

14. R. P. Drake, J. H. Hammer, C. W. Hartman, L. J. Perkins, D. D. Ryutov, Fusion Tech. 30, 310 (1996).

15. D. D. Ryutov and R. E. Siemon, Comments Plasma Phys. Cont. Fusion Comments Mod. Phys. 2, C185 (2001).

16. D. D. Ryutov, D. C. Barnes, B. S. Bauer, J. H. Hammer, C. W. Hartman, R. C. Kirkpatrick, I. R. Lindemuth, V. Makhin, P. B. Parks, D. B. Reisman, P. T. Sheehey, R. E. Siemon, $19^{\text {th }}$ IAEA Fusion Energy Conference, Lyon, France 1419 Oct. 2002, Paper IAEA-CN-94/IF/P12.

17. M. J. Taccetti, "Overview of High-density FRC Research on FRX-L at LosAlamos National Laboratory," LA-UR-02-6305, US/Japan CT Workshop Proceedings, Osaka University, Osaka, Japan, Sept. 2002 (to be published).

18. J. H. Degnan, et al., Phys. Rev. Letters, 82, 2681 (1999).

19. J. M. Taccetti, T. P. Intrator, F. J. Wysocki, K. C. Forman, D. G. Gale, S. K. Coffey, and J. H. Degnan, Fusion Science and Techn. 41, 13 (2002).

20. T. Intrator, et al., Nucl. Fusion 42, 211 (2002).

21. Descriptions and references can be found in R. E. Siemon, et al., "The relevance of Magnetized Target Fusion (MTF) to practical energy production," LANL report LA-UR-99-2956 (1999).

22. P. J. Turchi, "A compact-toroid fusion reactor design at 0.5 Megagauss, based on stabilized liner implosion techniques," Proc. $3^{\text {rd }}$ Intern. Conf. on Megagauss Magnetic Field Generation and Related Topics," Moscow, Nauka Publ. House (1984).

23. T. K. Fowler, "Pulsed Spheromak Reactor with Adiabatic Compression," LLNL report UCRL-ID-133884 (March, 1999).

24. U. Shumlak and C. W. Hartman, Phys. Rev. Letters 75, 3285 (1995). See also T. D. Aber and D. F. Howell, Phys. Rev. Lett. 76, 2198 (1996) and U. Shumlak and C. W. Hartman, Phys. Rev. Lett. 76, 2199 (1996).

25. T. D. Arber and D. F. Howell, Phys. Plasmas 3, 554 (1996).

26. U. Shumlak, R. P. Golingo, B. A. Nelson, and D. J. Den Hartog, Phys. Rev. Letters 87, 205005-1 (2001). See also, U. Shumlak, et al., “Evidence of 
Stabilization in the ZAP Flow Z-Pinch Experiment," Innovative Confinement Concepts Workshop, College Park, MD, 22-24 Jan. 2002,

https:// wormhole.ucllnl.org/ICC2002/.

27. C. W. Hartman, J. L. Eddleman, A. A. Newton, L. John Perkins, and U. Shumlak, Comments Plasma Phys. Controlled Fusion 17, 267 (1996). See also C. W. Hartman, J. L. Eddleman, R. Moir, and U. Shumlak, Fusion Tech. 26, 1203 (1994). 